\title{
3D Printing and Its Disruptive Impacts on Supply Chains of the Future Sebastian Mohr and Omera Khan
}

\author{
"One has to passionately believe it is possible to") \\ change the industry, to turn it on its head, to make \\ sure that it will never be the same again.
}

Richard Branson

Entrepreneur, investor, and philanthropist

\begin{abstract}
3D printing technology has emerged as one of the most disruptive innovations to impact the global supply chain and logistics industry. The technology is impacting our personal and professional lives, with some claiming that the technology will revolutionize and replace existing manufacturing technologies, while others argue that the technology merely enhances some aspects of the production process. Whether evolutionary or revolutionary, $3 \mathrm{D}$ printing technology is recognized as a striking trend that will significantly impact supply chains. Although the expansion of 3D printing in the private consumer market is an interesting development in its own right, the biggest potential for disruption lies in industrial applications and how 3D printing will influence supply chains of the future. In this article, we examine the areas of the supply chain most likely to be disrupted by 3D printing technology and we identify the key questions that must be answered in a roadmap for future research and practice. While we seek answers to these questions, we suggest that managers should develop a flexible change management strategy to mitigate the effects of disruption to their future supply chains and take advantage of the resulting opportunities. Those that do nothing will be left wanting, because the influence of 3D printing technology on supply chains is expected to grow.
\end{abstract}

\section{Introduction}

The concept of disrupting established systems and paradigms with innovative ideas and technologies has been prevalent throughout the history of mankind and is far older than any research documented about this topic. One of the earliest examples of this concept is the shift from hunter-gatherer groups to agricultural communes, which occurred approximately 12,000 years ago (Alday Ruiz, 2005), and well documented cases from more recent eras include the development of the Gutenberg printing press in the middle ages (Samuelson, 2000) as well as the invention of steamboats and the automobile (Mowery \& Rosenberg, 1999) in the 19th century. Industrialization has been a strong enabler of innovation and technology disruption (Mowery \& Rosenberg, 1999), with prominent examples being Henry Ford's factory and assembly line concept, which revolutionized industrial manufacturing (Batchelor,
1994) and the Microsoft operating system, which accelerated the adoption of personal computing (Chesbrough, 2003), thereby changing established paradigms and the status quo.

In modern times, cases of innovation disruption have become more frequent (Watson, 2012) with novel technologies such as the Internet of Things, autonomous machines, and high-end sensor technology being developed at a fast pace and applied in a wide range of different areas. 3D printing is one of these new, innovative technologies and it has made its mark on the industrial sector as well as the commercial market. The core principle of this method is that materials are added rather than subtracted from a larger raw material object during the manufacturing process, as is the case with conventional manufacturing; hence, $3 \mathrm{D}$ printing is synonymous with the term "additive manufacturing" (Campbell et al., 2011). It has successfully disrupted the 


\section{D Printing and Its Disruptive Impacts on Supply Chains of the Future}

\section{Sebastian Mohr and Omera Khan}

prototyping industry and given birth to new fields in the areas of design and manufacturing. With the ongoing improvement of 3D printers in terms of accuracy, speed, and quality, the potential for future impact is immense (Mohr, 2015).

It is of paramount importance that we explore what aspects of the supply chain have the potential to be disruptive so that managers can be adequately prepared and agile to adapt to a changed environment. In this article, we share our views on the impact of 3D printing technology as a potentially disruptive innovation, which have been created through an extensive examination of the literature, research outcomes of a Master's thesis on the topic, and our discussions with experts in the field. Through a synthesis of the relevant literature, we identify seven key areas likely to be impacted by $3 \mathrm{D}$ printing technology:

\section{Mass customization}

\section{Resource efficiency}

\section{Decentralization of manufacturing}

4. Complexity reduction

5. Rationalization of inventory and logistics

6. Product design and prototyping

\section{Legal and security concerns}

For each impact area, we list and discuss a number of trends that we can expect to see driving these impacts. Then, we conclude by presenting a roadmap of key questions concerning the aspects of the supply chain that have the biggest potential of disruption.

\section{Impact Area 1: Mass Customization}

3D printing can have remarkable impacts on downstream sections of the supply chain, such as production and distribution. Tailoring individualized offers to each customer and the involvement of clients in design and production activities hold potential for a shift in priorities of cost and profit management, and late-stage postponement can make the supply chain more agile and flexible to react to changes in the marketplace (Petrick \& Simpson, 2013).

Trends driving the impact

- The value proposition of this customization principle is the inclusion of the customer into the design process, or in other words, the initiation of customer cocreation (Beyer, 2014).

- Customer involvement could potentially change underlying assumptions of supply chain strategies, redefining the "how, where, and who" of an established supply chain structure; thus, it may also change management priorities (Nyman \& Sarlin, 2014).

-3D printing could blur the line between purchase and creation, or in supply chain terms, it could merge design, manufacturing, and distribution (Tien, 2012).

\section{Impact Area 2: Resource Efficiency}

As an additive manufacturing technology, 3D printing has greater resource efficiency compared to most conventional, subtractive production methods (Campbell et al., 2011). This has led some authors to propose that the rapid success of $3 \mathrm{D}$ printing will initiate a change of view on natural resources with respect to material savings during production, smart redesign of components, and the ability to utilize recycled materials for the printing process (Reeves, 2009; Wigan, 2014).

Trends driving the impact

- 3D printing could enhance the development of the concept of the circular economy and promote the utilization of recycled materials.

-3D printing produces less waste during manufacturing compared with conventional machines, thereby contributing to a greener, more environmentally sustainable technology (Janssen et al., 2014).

- Better use of postponement and late-stage customization through 3D printing could significantly reduce overproduction and excess inventory.

-3D printing as a portable manufacturing technology will take production closer to the market, thus reducing global footprint of the supply chain and a reduction in carbon emissions (Petrick \& Simpson, 2013).

\section{Impact Area 3: Decentralization of Manufacturing}

The relocation of manufacturing through 3D printing can bring considerable benefits in the form of onlocation production and consumption as well as quicker responses to changes in demand. Reshoring manufacturing with 3D printing can improve time-to-market, 


\section{D Printing and Its Disruptive Impacts on Supply Chains of the Future}

\section{Sebastian Mohr and Omera Khan}

responsiveness, and the degree of agility in the supply chain for small volumes of products, particularly those that require high technological specifications (Garrett, 2014).

\section{Trends driving the impact}

- The high ratio of output volume to space occupied makes the technology an enabler of distributed manufacturing (Birtchnell et al., 2013).

-3D printing is useful for manufacturing in difficult-toreach locations or in humanitarian logistics after a natural disaster (Tatham et al., 2014).

-3D printing technology does not require the same skills as conventional manufacturing; manufacturing could be re-shored and take place closer to customers in their home markets, mitigating the risks of obsolescence.

\section{Impact Area 4: Complexity Reduction}

$3 \mathrm{D}$ printing is a powerful tool to reduce complexity in the supply chain, from the consolidation of components into a single product: by replacing previously assembled parts with a single component, the manufacturing process can be simplified significantly (Gao et al., 2015). Consequently, there is great potential for savings on internal cost and time through reduced supply chain complexity.

\section{Trends driving the impact}

- Component consolidation lowers not only the number of components in the manufacturing flow, it can also permanently reduce the number of stock keeping units (SKUs) in the system.

-3D printing replaces many of the assembly steps required during the production phase in the supply chain with a single task; therefore, process complexity is reduced, making the flow of the material more transparent and easier to control (Janssen et al., 2014).

\section{Impact Area 5: Rationalization of Inventory and Logistics}

3D printing allows for production to happen on demand and at the point of consumption; therefore, the need to transport physical goods can be replaced by placing manufacturing close to the customer, which would lead to the rationalization of warehousing and logistics (Manners-Bell \& Lyon, 2012). Furthermore, the movement of physical goods across the globe can be substituted by sending electronic files for the printers (Nyman \& Sarlin, 2014). Digital inventory in the form of 3D model files for the entire product portfolio could replace physical inventory for technically complex products, further reducing the number of SKUs and the total number of stored parts.

\section{Trends driving the impact}

- The combined effects of 3D printing on various sections of the supply chain could potentially initiate a decrease in demand for global transportation of physical goods and inventory activities.

- 3D printing will have an impact on the volume of the inventory and on the inventory mix, including a shift to inventory in the form of raw materials (e.g., powders or filament coils) rather than semi-finished parts and components. The handling of these raw materials is cheaper, safer, and requires lesser skilled workers than the handling of semi-finished goods and final products.

\section{Impact Area 6: Product Design and Prototyping}

Because 3D printing technology is so versatile, it can produce a vast range of fundamentally different outputs cheaply, easily, and quickly. Therefore, 3D printers can play a key role in creating innovative processes for manufacturing and testing prototypes as well as new or updated product designs (Berman, 2012; Lee, 2013). 3D printing can also be used in direct manufacturing of products or product components (General Electric, 2015). This is primarily the case for product modules with a high need for customizability and a high degree of complexity, but comparatively low production volumes.

\section{Trends driving the impact}

- Due to its additive nature and direct digital-to-physical concept, product designers are no longer tied to traditional constraints imposed by production such as "design for manufacturing"(Mohr, 2015). Instead, many products can be redesigned almost entirely with a focus on other critical aspects such as enhanced functionality and material savings without compromising any of the attributes.

- Customer involvement in the design process will create "prosumers": individuals who are actively involved in the creation of a product while at the same being its main consumers. 


\section{D Printing and Its Disruptive Impacts on Supply Chains of the Future}

\section{Sebastian Mohr and Omera Khan}

\section{Impact Area 7: Legal and Security Concerns}

Legal concerns have been and will continue to be an important topic of discussion in relation to 3D printing (Dante, 2014; Schildhorn, 2014). Some researchers argue that anything that can happen, will happen, including the printing of harmful objects such as guns or the bypassing of legal checks built into a traditional supply chain (Schildhorn, 2014). Furthermore, due to the fact that the current underlying legal framework does not consider the copying of physical objects, it is illequipped to define clear rules for the use of $3 \mathrm{D}$ printers. For example, who is held responsible for the printing of harmful objects such as knives and guns? Or, who is to blame if a 3D printed product fails: the designer, the printing machine manufacturer, the material supplier, or the company printing and selling the product? Thus, there is great uncertainty regarding the future impacts in areas such as personal injury, intellectual property theft, and product liability.

\section{Trends driving the impact}

- The technology is becoming more and more mainstream with the spread of open source modelling software and sharing platforms for 3D files, enhancing the risk of legal misconduct (Dante, 2014).

- Scanning technology that is used to transform physical objects into digital 3D printing files with ease is experiencing rapid development (Nyman \& Sarlin, 2014).

\section{Conclusion}

The impacts described above illustrate why 3D printing has enormous potential to disrupt the status quo. This disruptive innovation threatens not only the established paradigms in the manufacturing industry, but also applies to legal and security concerns. With 3D printing technology being well established in many industrial production companies looking for new, innovative ways to expand the purpose of this technology and with $3 \mathrm{D}$ printing making a strong move into the commercial consumer market, this disruption could unfold sooner rather than later. It is likely that we will see a variety of disruptive, innovative ideas originating from new applications surrounding this technology, and although the future developments are highly uncertain, they are certainly worth investigating and discussing. In Table 1, we identify the key questions that must be answered in a roadmap for future research and practice so that researchers and managers can mitigate the negative impact of disruption or take advantage of its resulting opportunities. Although this disruptive innovation could be devastating for some elements of the supply chain, it can be the start of a revolution for others. Thus, supply chain managers must be aware of the potential impacts that this technology could have on their organization and accordingly, be prepared to react in a flexible and adaptive manner.

Table 1. Key unanswered questions about the disruptive impacts of 3D printing on future supply chains

\begin{tabular}{ll}
\hline Aspect & Questions \\
\hline Manufacturing & - How will the emergence of 3 D printing enable other innovations in this sector? \\
\hline - What knock-on effects will the disruption of manufacturing have in other areas? \\
\hline Dispersed manufacturing & - How will the local-for-local business model affect global logistics activities? \\
\hline Design & - How will 3D printing continue to drive innovation in product design? \\
\hline Shift in skill requirements & - Which industries/product groups will be most affected by new designs? \\
\hline Sustainability & - What will happen to the majority of the workforce in low-cost countries? \\
\hline Legal/security concerns & $\begin{array}{l}\text { - Wow will material savings and smart designs affect production in the long run? } \\
\text { - Wow are the total costs of ownership defined? }\end{array}$ \\
\hline
\end{tabular}




\section{D Printing and Its Disruptive Impacts on Supply Chains of the Future}

\section{Sebastian Mohr and Omera Khan}

\section{About the Authors}

Sebastian Mohr is a management consultant specializing in procurement and supply chain management with an educational background in operations research and mathematical modelling from the Technical University of Denmark. His focus area is supply chain and procurement optimization, and in this context, he has a broad experience working on projects in various industries across Denmark and Germany. His main area of research revolves around the impact of future technology on supply chains and supply chain management.

Omera Khan is a Full Professor of Operations Management at the Technical University of Denmark. She works with leading organizations on a range of supply chain and logistics issues and is advisor to many universities developing courses in logistics, supply chains, and operations management. She has led and conducted research projects commissioned by government agencies, research councils, and companies in supply chain resilience, responsiveness, sustainability, and the impact of product design on the supply chain. Her latest area of research focuses on cyber-risk and resilience in the supply chain and the impact of emerging technologies on supply chains of the future. Omera is an advisor to many organizations and provides specialist consultancy in supply chain risk management. She is a highly acclaimed presenter and is regularly invited as a keynote speaker at global conferences and corporate events. She has published her research in leading journals, contributed to several book chapters, and is lead author of Handbook for Supply Chain Risk Management: Case Studies, Effective Practices and Emerging Trends. She founded and was Chair of the Supply Chain Risk and Resilience Research Club and the Product Design and Supply Chain Special Interest Group. Omera is a Chartered Fellow of the Chartered Institute of Logistics and Transport and a Fellow of the Institute of Operations Management.

\section{References}

Alday Ruiz, A. 2005. The Transition Between the Last HunterGatherers and the First Farmers in Southwestern Europe: The Basque Perspective. Journal of Anthropological Research, 61(4): 469-494.

Batchelor, R. 1994. Henry Ford: Mass Production, Modernism, and Design. Manchester, UK: Manchester University Press.

Berman, B. 2012. 3-D Printing: The New Industrial Revolution. Business Horizons, 55(2): 155-162.

http://dx.doi.org/10.1016/j.bushor.2011.11.003

Beyer, C. 2014. Strategic Implications of Current Trends in Additive Manufacturing. Journal of Manufacturing Science and Engineering, 136(6): 064701. http://dx.doi.org/10.1115/1.4028599

Birtchnell, T., Urry, J., Cook, C., \& Curry, A. 2013. Freight Miles: The Impact of $3 D$ Printing on Transport and Society. Report: ESRC Project ES/J007455/1. Lancaster, UK: Lancaster University; Economic \& Social Research Council; The Futures Company.

Campbell, T. S., Williams, C., Ivanova, O., \& Garrett, B. 2011. Could 3D Printing Change the World? Technologies, Potential, and Implications of Additive Manufacturing. Washington, DC: Atlantic Council.

Chesbrough, H. W. 2003. The Era of Open Innovation. MIT Sloan Management Review, 44(3): 35-41.

Dante, W. 2014. Top 10 3D Printing Industry Trends for 2015 - 3D Printing Predictions. Association of $3 D$ Printing, December 29, 2014. Accessed November 1, 2015:

http://associationof3dprinting.com/top-10-3d-printing-industrytrends-for-2015-3d-printing-predictions/.

Gao, W., Zhang, Y., Ramanujan, D., Ramani, K., Chen, Y., Williams, C. B., Wang, C. C. L., Shin, Y. C., Zhang, S., \& Zavattieri, P. D. 2015. The Status, Challenges, and Future of Additive Manufacturing in Engineering. Computer-Aided Design, 69: 65-89. http://dx.doi.org/10.1016/j.cad.2015.04.001

Garrett, B. 2014. 3D Printing: New Economic Paradigms and Strategic Shifts. Global Policy, 5(1): 70-75.

http://dx.doi.org/10.1111/1758-5899.12119

General Electric. 2015. Transforming Manufacturing, One Layer at a Time. General Electric: Advanced Manufacturing. Accessed November 1, 2015:

http://www.ge.com/stories/advanced-manufacturing

Janssen, G. R., Blankers, I. J., Moolenburgh, E. A., \& Posthumus, A. L. 2014. TNO: The Impact of 3-D Printing on Supply Chain Management. The Hague, Netherlands: TNO.

Lee, L. 2013. 3D Printing - Transforming The Supply Chain: Part 1. IBM Insights on Business: Electronics Industry, April 26, 2013. Accessed November 1, 2015:

http://insights-on-business.com/electronics/3d-printingtransforming-the-supply-chain-part-1/

Manners-Bell, J., \& Lyon, K. 2012. The Implications of 3D Printing for the Global Logistics Industry. Bath, UK: Transport Intelligence.

Mohr, S. 2015. The Impact of 3D Printing on Future Supply Chains. Master's Thesis, Technical University of Denmark, Copenhagen. 


\section{D Printing and Its Disruptive Impacts on Supply Chains of the Future Sebastian Mohr and Omera Khan}

Mowery, D. C., \& Rosenberg, N. 1999. Paths of Innovation: Technological Change in 20th-Century America. Cambridge, UK: Cambridge University Press.

Nyman, H. J., \& Sarlin, P. 2014. From Bits to Atoms: $3 D$ Printing in the Context of Supply Chain Strategies. Paper presented at the 47th Hawaii International Conference on System Sciences, Waikoloa, HI, January 6-9, 2014: 4190-4199.

http://dx.doi.org/10.1109/HICSS.2014.518

Petrick, I. J., \& Simpson, T. W. 2013. 3D Printing Disrupts Manufacturing: How Economies of One Create New Rules of Competition. Research-Technology Management, 56(6): 12-16.

Reeves, P. 2009. Additive Manufacturing - A Supply Chain Wide Response to Economic Uncertainty and Environmental Sustainability. Wirksworth, UK: Econolyst Limited.

Samuelson, R. J. 2000. The Internet and Gutenberg. Newsweek, January 23, 2000. Accessed November 1, 2015:

http://www.newsweek.com/internet-and-gutenberg-158401
Schildhorn, Z. 2014. 5 Trends to Watch for in 3D Printing in 2015. VentureBeat, December 20, 2014. Accessed November 1, 2015: http://venturebeat.com/2014/12/20/5-trends-to-watch-for-in-3dprinting-in-2015/

Tatham, P., Loy, J., \& Peretti, U. 2014. 3D Printing (3DP): A Humanitarian Logistic Game Changer? 12th ANZAM Operations, Supply Chain and Services Management Symposium. Auckland, Australia: Australian \& New Zealand Academy of Management.

Tien, J. M. 2012. The Next Industrial Revolution: Integrated Services and Goods. Journal of Systems Science and Systems Engineering, 21(3): 257-296.

http://dx.doi.org/10.1007/s11518-012-5194-1

Watson, J. 2012. Agent of Change: The Future of Technology Disruption in Business. London: Economist Intelligence Unit.

Wigan, M. R. 2014. Transport Replacement and Sustainability Aspects Associated with Additive manufacturing. SelectedWorks of Marcus $R$ Wigan. Accessed November 1, 2015:

http://works.bepress.com/mwigan/6/ 